\title{
Congress Presidents Nikolas Papantoniou and Christoph F Dietrich warmly invite you to EUROSON 2015, Athens, Greece 6-8 November 2015
}

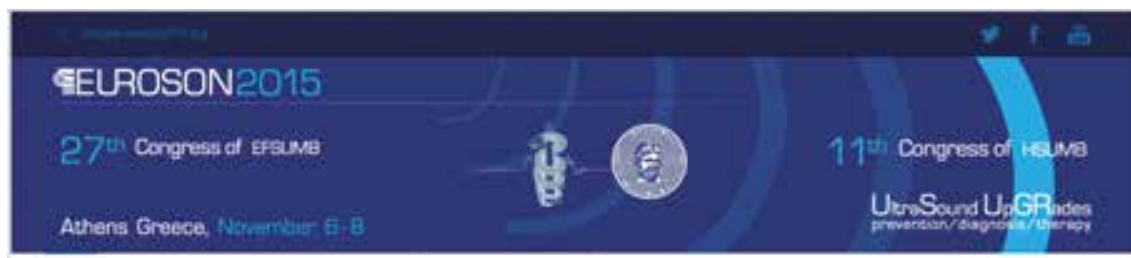

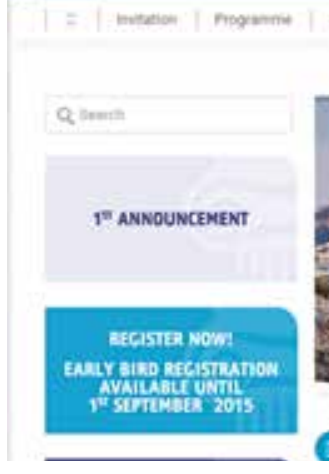

Key dates

- Registration is now open - early bird registration open until 1 September

- Abstracts are invited - deadline 15 June

- Congress - 6-8 November

Venue

Athens Hilton Hotel

\section{Accommodation}

Apart from the Athens Hilton accommodation is available for all budgets within walking distance from the Congress with attractive rates - Best Western Ilisia, Golden Age or Stratos Vassilikos

\section{Programme}

$$
\nabla
$$

Categorical Courses/Refresher Courses/Symposia/Special Focus Sessi-
ons/Scientific Sessions/Invited Lectures/How to do-Practical Courses/Mini Courses / Multidisciplinary Sessions / Plenary Sessions / e-posters

In co-operation with the Societies of

$\nabla$

- Gynaecology-Obstetrics Surgery

- Gastroenterology

- Endocrinology/Orthopaedics

- Cardiology

- Breast Surgery

- Oncology

- Neurology

- Dermatology

- Anaesthesiology

- Vascular Surgery

Organised by

- The Hellenic Society for Ultrasound in Medicine and Biology www.hsumb. gr/info@hsumb.gr
- President Nikolaos Papantoniou, Professor of Gynaecology

- A. N. Chalazonitis, Radiologist \& President of EUROSON 2015 Scientific Committee

- Vice-president Irene Mastorakou, Radiologist

- Secretary General Konstantinos Vagianos, Professor of Surgery

- Treasurer Eleni Panteleakou, Radiologist

- Maria Travassarou, Neurologist

10 Categorical Courses

- CC1 - BREAST

- CC2 - OBGYN

- CC3 - MSK US

- CC4 - CARDIOVASCULAR

- CC5 - UPPER ABDOMEN - Ultrasound Assessment of the Upper Abdomen and GI-Tract

- CC6 - TRAUMA ICU

- CC7 - UROLOGY

- CC8 - HEAD AND NECK

- CC9 - US IN ANAESTHETIC PRACTICE

- CC10 - INTERVENTIONAL ULTRASOUND

\section{US Course example}

Categorical Course 2 OB / GYN

A.CNS

1. Fetal Brain I: Ventriculomegaly \& Agenesis of the Corpus Callosum 
2. Fetal Brain II: Posterior Fossa Abnormalities

3. Neural tube defects - Spinal Cord

4. CNS abnormalities at 11-14 weeks

B. Thorax - Abdomen-Skeleton

1. Diaphragmatic Hernia, CCAM \& Pleural effusion

2. Craniofacial anomalies

3. GI \& Genito-urinary tract

4. Skeletal Dysplasia

C. Fetal Heart

1. Examination of fetal heart in the 2 nd trimester

2. Fetal Heart \& Chromosomal Abnormalities

3. First trimester Screening for fetal heart anomalies

4. Common Congenital Defects

5. First Trimester Detection of CHD

D. US in Obstetrical Management

1. First term miscarriage and Ectopic pregnancy: ultrasound criteria and management

2. Biophysical profile \& Doppler in management of IUGR

3. Preterm Labour

4. Ultrasound in Labour

5. Trophoblasic Disease and Caesarean Scar Pregnancy

E. Multiple Pregnancy

1. Multiple pregnancy: the basics

2. Screening for chromosomal abnormalities in

3. First trimester screening for TTTS

4. Management and Complications in monochorionic twins

\section{Refresher Course 2 - OBGYN}

A. Screening in Obstetrics

1. What should not be missed from fetal anatomy in the 1 st trimester

2. The first trimester scan: time for a rethink

3. Screening for preterm delivery

4. The role of Amniocentesis and CVS in the era of non invasive prenatal testing (NIPT)

B. "Ultrasound in Gynecology"

1. Classifying Ovarian Pathology by ultrasound

2. Evaluating cervical neoplasia by color Doppler -Elastography

3. Diagnosing fibroids, sarcoma and adenomyosis with ultrasound

4. Ultrasound of Pelvic floor disorders

5. The role of ultrasound in the diagnosis of endometriosis
C. US Guided Invasive Diagnostic and Therapeutic Procedures during Pregnancy

1. Amniocentesis vs CVS

2. Fetal Blood Sampling and intrauterine transfusions

3. Sonographic Evaluation \& Management in TTTS

4. Shunting in Pleural effusions CCAM

5. Us Guided Invasive Procedures in Fetal Obstructive Uropathy

D. Ultrasound in High Risk Pregnancy

1. Screening of Pre-eclampsia in the First Trimester

2. Ultrasound for Fetal Growth/IUGR

3. Placenta; Umbilical Cord; Amniotic Fluid

4. Elastography of the cervix and prediction of preterm labor

Practical Course 2 - OBGYN Obstetrics

1. US in obstetrics / 1st trimester

2. US in 2nd trimester pregnancies

3. Fetal Heart

4. Amniocentesis/CVS/FBS

\section{Gynecology}

1. 2D 3D Color Doppler Evaluation of the Ovaries

2. 2D 3D Evaluation of with Color Doppler of the Uterine Body Cervix

3. Elastography of the Uterine Body and Ovaries

\section{Refresher Courses}

In addition to the categorical course topics there will be refresher courses in Elastography / IntestinalUltrasound / Physics / Neurosonology. During the congress EFSUMB and ENSCH will present new ultrasound guidelines.

\section{Workshops/Practical Courses}
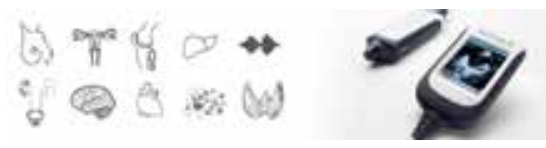

The aim of each practical Course is to explain and familiarise the attendees on Ultrasound and US guided Interventional Techniques. The Practical Course starts with 3 short How-to-do Practical Presentations. Then the Instructors are showing the participants in real time double projection the handling of the transducer. Tips \& Tricks of each technique and method are explained. Finally, the audience is asked to actively participate in examinations using 6 different US machines and different transducers on real-life conditions, on models or phantoms.

\section{Prizes at EUROSON 2015}

- The Walter Krienitz Society offers $500 €$ for the best oncological abstract submitted to the Congress

- EFSUMB offer $500 €$ which will be awarded for the best published paper

- Young Investigator Award of $1000 €$ for the best presentation

(see www.efsumb.org for more information)

\section{Satellite Symposium}

Samsung, Bracco and Toshiba are each sponsoring a lunchtime symposium.

State of the Art Lecture Prof Jung Hwan Baek of Soeul, Korea will be demonstrating his innovative techniques of ultrasound guided thyroid ablation.

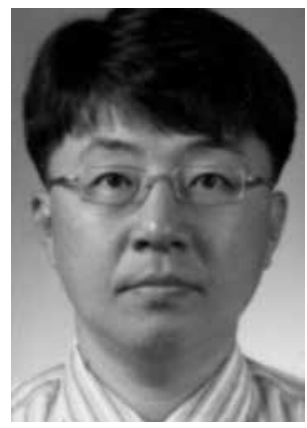

\section{Students}

A special rate has been assigned for medical students to attend on Sunday 8 November. To see the registration rates visit the website www.euroson2015.org

\section{Last but not least}

The Athens Marathon takes place on Sunday 8 November and passes the Athens Hilton beside which stands the glass and iron sculpture Dromeas (Runner) created by Athens artist Costas Varotsos.

\section{See you in Athens}

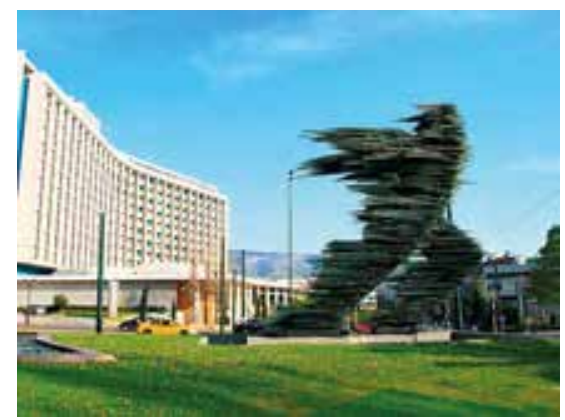

